\title{
Recommender Systems: Are Users Taking the Recommendations Seriously?
}

\author{
Dr. Deepak. R* and Aishwarya Korishettar
}

\author{
Department of Management Studies, Dayananda Sagar College of Engineering, \\ Bangalore, India.
}

\section{Article Type: Article}

Article Citation: Dr. Deepak. Rand Aishwarya Korishettar, Recommender Systems: Are Users Taking the Recommendations Seriously? ISBR Management Journal. 2021; 6(01), 27-33. D01: 10.52184/isbrmj.v6i1.108

Received date: March 20, 2021

Accepted date: April 25, 2021

*Author for correspondence: Deepak.R deepak-mbavtu@ dayanandasagar.edu 9 Department of Management Studies, Dayanand Sagar College of Engineering, Bangalore, India

\begin{abstract}
In recent years, we have observed substantial choices provided to consumers due to the rise of e-commerce. The products and the product-related suggestions provided by the various recommender systems have been found to be noteworthy given the enormous data available and information overload. The customers are not worried about the complexity of these algorithms but want the automated process to recommend product-related items of their choices. The study is an attempt to understand whether customers make purchase decisions online using the suggestions recommended across various product lines. For the study, responses of the customers were collected using a structured questionnaire and results were analysed to examine if respondents of different demographic characteristics make purchase related decisions based on the suggestions by recommendation systems.
\end{abstract}

Keywords: Recommendation System, E-commerce, Purchase Decisions

\section{Introduction}

Recommendation systems are observed to be the most popular analytical tool nowadays which has been utilized in helping companies generate more income online than offline. They provide an ambient environment to create a rundown of suggested things. These applications help explicitly to address various inclinations of the customers such as things they have seen, a segment they have visited, their subject interests, etc. In recent years, companies such as Amazon, Flipkart are using suggestion calculations to customize the online store for every client and thus are moving towards personalization. Schafer, Konstan, and Riedl (1999) examined how recommender systems help E-commerce sites increase sales, and analyzed six sites that use recommender systems including several sites that use more than one recommender system. Thus, depending on the customers' interests, the recommendation systems will recommend titles, toys, books, etc. But, how appropriate are these recommendations?. Schafer, Konstan, and Riedl (2001) presented an explanation of how recommender systems are related to some traditional database 
analysis techniques. The paper examined how recommender systems help E-commerce sites increase sales and analyze the recommender systems at six market-leading sites. They identified five commonly used E-commerce recommender application models and described several open research problems in the field of recommender systems, and examined privacy implications of recommender systems technology.

Do customers actually look into the suggestions and buy things is a question of relevance today? Schafer et al. (1999) created a taxonomy of recommender systems and examined the interfaces and technologies which can be used to create the recommendations. Compared to the last five years, the businesses have been operating in a very challenging environment given the tremendous measures of information across several clients. The business wants specifically these applications to return the outcomes progressively in the first portion compared to the second, thus delivering greater suggestions. (Neumann, 2008). These suggestions can then be used as a designated promoting instrument in various digital marketing methods such as sending emails. Schafer et al. (2001) concluded that recommender systems are being effectively used by an ever-increasing number of E-commerce sites and have been used as a very serious business tool.

We might notice that when we visit Amazon.com landing page, tapping into "Your Recommendations" will automatically connect customers to their suggestions in the form of product offering, rating the suggested items, their rating of past buys, etc. Thus, Amazon.com broadly utilizes proposal calculations to customize its Web webpage to every client's advantage. Thus, recommendation systems thus help in timely delivering excellent proposals continuously. Zhang and Jiao (2007) proposed an associative classificationbased recommendation system for personalization in $\mathrm{B} 2 \mathrm{C}$ e-commerce applications. The paper proposed by the system provided the analysis, design, and implementation issues in an Internet programming environment.

Though in reality, in the case of offline purchases, a recommendation as a social process plays an insignificant role and we notice that people rely on external knowledge to make the decisions about an artifact of interest. Recommender systems have been observed to provide great opportunities to businesses and therefore research on developing new recommender system techniques and methods have been receiving increasing attention (Jin and Byeong-Woon, 2017). Recommendation techniques can be classified into three major divisions: Collaborative Filtering, Content Based, and Hybrid Recommendations. Each method has its advantages and limitations. According to Jiang, Cheng, and Yang (2018) the scope for one algorithm to perform the recommendation tasks is not only easy to implement but also prediction accuracy can come down significantly. They proposed a slope one algorithm based on the fusion of trusted data and user similarity, which can be deployed in various recommender systems.

\section{Problem Statement}

E-commerce companies such as Amazon, Flipkart, e-sound and so on are placing a great deal of cash into recommendation system framework so that they can entice customers to purchase more things. These enticing methods engross customers by giving great 
suggestions on, either films, apparels, electronics. All customers from old to young have a clear understanding of the recommendation systems and how they help in making better decisions. But, would customers really think they would deviate from these recommendations and make their own decisions is one key marketing question that would help in making better altercations to algorithms already deployed in the industry.

\section{Objectives of the Study}

1. To understand whether customers do follow the recommendations provided in various interfaces in making related purchases when prompted.

2. To analyze user's behavioral patterns and propose new altercations if any, to the existing algorithms.

\section{Hypothesis of the Study}

$\mathrm{H}_{0}$ : Recommendation systems are not reliable to address various inclinations of the customers towards related products purchases across various interfaces.

$\mathrm{H}_{1}$ : Recommendation systems are reliable to address various inclinations of the customers towards related products purchases across various interfaces.

\section{Data Collection and Methodology}

\subsection{Data Collection}

This is descriptive research involving the data collection from primary as well as secondary sources. In the case of primary data collection, a well-structured questionnaire was prepared and data was collected. For the study, the population comprises all the respondents who purchase products mainly online on various E-commerce websites in Bengaluru city. In order to examine the reliability of the recommendation systems on the customer choices, the data of 88 respondents was collected using a structured questionnaire administered online using google forms. Secondary information was gathered from various secondary sources such as journals, websites, research articles, books etc.

\subsection{Sampling Procedure and Methodology}

The sampling procedure followed in the study is a non-probability convenient sampling method. The respondents were selected from the database available by using some key demographic variables such as educational qualification, occupation, and residence. The responses obtained were analyzed using standard techniques of descriptive statistics, cross-tabulation, and chi-square analysis. 


\section{Data Analysis and Interpretations}

Since the study was conducted during the pandemic period during January 2021 and May 2021, the majority of the purchases made by the consumers online were related to groceriesbased purchases. Out of a total of 88 respondents, the majority of the respondents made groceries based purchases online more often when compared to other categories such as mobiles, fashion apparels, electronics, appliances etc. The top 15 Products which belonged to both groceries and personal care have been shown in Table $\mathbf{1}$ below.

TABLE 1. Products brought by the respondents on E-Commerce sites.

\begin{tabular}{lc}
\hline The factors considered more important (Rank 1) \\
\hline Variable & Percentage (\%) \\
Groceries & 44.3 \\
Oil and Ghee & 10.2 \\
Tea and Coffee Powder & 10.2 \\
Hand Sanitizer and Mask & 8 \\
Biscuits & 5.7 \\
Energy and Soft Drinks & 4.5 \\
Sanitary Napkins and Diaper & 2.3 \\
Atta and Flour & 3.4 \\
Noodles and Pasta & 3.4 \\
Soaps and Shampoo & 2.3 \\
Dal and Pulses & 1.1 \\
Spices & 1.1 \\
Laundry Detergent & 1.1 \\
Dishwashing & 2.2 \\
\hline
\end{tabular}

It is quite evident that, since the responses were obtained mainly during the lockdown phase, we see impulsive purchasing and storage of essential items. It was also seen that people started to use E-Commerce sites for contactless delivery. This study was mainly focused on seeing how the recommendation system helps in purchasing essential items segment. Out of 50 essential items, 15 essential items were bought more often. The market basket recommendations were found to have been very convenient to the majority of the respondents in making product-related purchases.

\subsection{Gender of the Respondents}

TABLE 2. Gender of the respondents.

\begin{tabular}{llllll}
\hline \multicolumn{5}{c}{ Gender of Respondents } \\
\hline & & Frequency & Percent & Valid Percent & $\begin{array}{l}\text { Cumulative } \\
\text { Percent }\end{array}$ \\
\hline Valid & Male & 46 & 52.3 & 52.3 & 52.3 \\
& Female & 42 & 47.7 & 47.7 & 100.0 \\
& Total & 88 & 100.0 & 100.0 & \\
\hline
\end{tabular}




\subsection{Age of the Respondents}

TABLE 3. Age of the respondents.

\begin{tabular}{|c|c|c|c|c|c|}
\hline \multicolumn{6}{|c|}{ Age of Respondents } \\
\hline & & Frequency & Percent & Valid Percent & $\begin{array}{l}\text { Cumulative } \\
\text { Percent }\end{array}$ \\
\hline \multirow[t]{8}{*}{ Valid } & Under 18 & 4 & 4.5 & 4.5 & 4.5 \\
\hline & $18-24$ & 24 & 27.3 & 27.3 & 31.8 \\
\hline & $25-34$ & 22 & 25.0 & 25.0 & 56.8 \\
\hline & $35-44$ & 10 & 11.4 & 11.4 & 68.2 \\
\hline & $45-54$ & 17 & 19.3 & 19.3 & 87.5 \\
\hline & $55-64$ & 9 & 10.2 & 10.2 & 97.7 \\
\hline & Above 64 & 2 & 2.3 & 2.3 & 100.0 \\
\hline & Total & 88 & 100.0 & 100.0 & \\
\hline
\end{tabular}

Since we were mainly looking into awareness of the recommendations systems across the various demographics, we have tried to ensure that responses were obtained from all the major sections of age demographics initially created. As observed, there is equal representation in terms of Gender as observed in Table 2. As observed from Table 3 we can notice that more than 70 percent of the respondents are under the age group of 44 years who often use E-commerce sites for shopping.

\subsection{Awareness of In-Built Recommendation System in E-Commerce Site}

TABLE 4. Awareness of In-built recommendation system in E-commerce site.

\begin{tabular}{llllll}
\hline \multicolumn{5}{c}{ Did you know that E-Commerce site has In-built recommendation system } \\
\hline \multirow{4}{*}{ Valid } & Frequency & Percent & Valid Percent & $\begin{array}{l}\text { Cumulative } \\
\text { Percent }\end{array}$ \\
\cline { 2 - 6 } & & & & 67.0 \\
& Yes & 59 & 67.0 & 67.0 & 100.0 \\
& No & 29 & 33.0 & 33.0 & \\
& Total & 88 & 100.0 & 100.0 & \\
\hline
\end{tabular}

From the analysis results obtained in Table 4, we can notice that most of the respondents are aware of the recommendation system being used and are aware of the suggestionsbased systems inbuilt which help them to purchase various relatable products and items together.

\subsection{Usage of Recommendation Systems on E-Commerce Sites for Purchasing}

TABLE 5. Usage of recommendations on E-Commerce site for purchasing.

Do you use recommendations made on E-Commerce site for related item purchases 
Recommender Systems: Are Users Taking the Recommendations Seriously?

\begin{tabular}{llllll}
\hline & & Frequency & Percent & $\begin{array}{l}\text { Valid } \\
\text { Percent }\end{array}$ & $\begin{array}{l}\text { Cumulative } \\
\text { Percent }\end{array}$ \\
\cline { 2 - 6 } Valid & Never & 3 & 3.4 & 3.4 & 3.4 \\
& Occasionally & 16 & 18.2 & 18.2 & 21.6 \\
& Sometimes & 24 & 27.3 & 27.3 & 48.9 \\
& Often & 31 & 35.2 & 35.2 & 84.1 \\
& Always & 14 & 15.9 & 15.9 & 100.0 \\
& Total & 88 & 100.0 & 100.0 & \\
\hline
\end{tabular}

From the results obtained in Table 5, we can notice that, majority of the respondents did use the online recommendation suggestions in making related purchases of items and products. More than 80 percentage of the respondents clearly agree to use recommendation systems for making related product purchases on e-commerce websites.

From the inference, it is clearly evident that respondents make purchase decisions using recommendation systems. What is very important to examine is, whether these decisions are clearly prominent across various age groups or not. Thus, the association relationship was conducted using cross-tabulation between age and usage of recommendations by respondents.

\subsection{Cross Tabulation Results Between Age and Purchase Decisions Made Using Recommendation Systems}

The hypothesis which was examined in this scenario is to find if purchasing decision of related products cuts across all the various age groups considered in the study.

$\mathrm{H}_{\mathrm{o}}$ : There is no significant relationship between Age and purchase decisions taken by the respondents based on recommendation systems.

$\mathrm{H}_{1}$ : There is significant relationship between Age and purchase decisions taken by the respondents based on recommendation systems.

TABLE 6. Chi-Square results between age and purchase decisions.

\begin{tabular}{llll}
\hline \multicolumn{4}{c}{ Chi-Square Tests } \\
\hline Value & df & $\begin{array}{l}\text { Asymptotic Significance } \\
\text { (2-sided) }\end{array}$ \\
\hline Pearson Chi-Square & $46.408^{\text {a }}$ & 24 & .004 \\
Likelihood Ratio & 44.608 & 24 & .006 \\
Linear-by-Linear Association & 2.605 & 1 & .107 \\
N of Valid Cases & 88 & & \\
\hline
\end{tabular}

As observed from Table 6 at $5 \%$ level of significance, we fail to accept the null hypothesis and accept the alternative hypothesis that, recommendation systems algorithms used by the various key prominent E-commerce players are very successful in making customers purchase relevant related products. The recommendation systems are clearly been successful in catering to the needs of the customer across various age groups as seen from the study. Similar results were also obtained when the analysis was conducted with respect to several key demographics such as the income of the respondents too. 


\section{Conclusion of the Study}

Recommender systems permit web-based businesses to gain more sales in recent years by being profoundly adaptable and adjustable to the growing associations between products and related items. The recommender algorithms used by the organizations have been able to more readily comprehend the choices of the customers and make it possible for personalization. This would thus result in incrementing consumer loyalty and faithfulness. The results of the study clearly show that recommendations made by the algorithms have been successful in executing existing information mining methods and have helped in adjusting them to current requirements. Thus, across various demographic groups, the recommendation systems have been able to utilize crossover sifting and reassuring the companies that, investment in technology has been clearly resulting in superior returns.

\section{Scope for Future Research}

1. The study can be conducted across various segment across the country to know their inclinations towards making product related purchases.

2. The study can be conducted across various product lines and across price segments to know the success of algorithms over a period of time.

\section{References}

Jiang, L., Cheng, Y., Yang, L. (2019). A trust-based collaborative filtering algorithm for E-commerce recommendation system. Journal of Ambient Intelligence and Humanized Computing, 10:30233034. doi: https://doi.org/10.1007/s12652-018-0928-7

Jin, B.-W., Cho, Y.-S., \& Ryu, K.-H. (2010). A personalized e-commerce recommendation system using RFM techniques and association rules. Journal of the Korean Society for Computer Information and Information Science, 15 (12), 227-235. doi: https://doi.org/10.9708/JKSCI.2010.15.12.227

Neumann, A. W. (2008). Recommender systems for scientific and technical information providers. Dissertation, Universit" at Karlsruhe (TH) Karlsruhe, Germany.

Schafer, J. B., Konstan, J. A., and Riedl, J. (1999). Recommender system in e-commerce. Proceedings of the ACM Conference on Electronic Commerce, ACM, 115-152.

Schafer, J. B., Konstan, J. A., and Riedl, J. (2001). E-commerce recommendation applications, Data Mining and Knowledge Discovery, 5:115-152. doi: 10.1023/A:1009804230409

Sivapalan, S., Sadeghian, A., Rahanam, H. (2014). Recommendation systems for E-commerce. Proceedings of 2014 World Automation Congress (WAC) Kona, Hawaii - Conference location, retrieved from https://www.researchgate.net/publication/266970881

Zhang, Y., Jiao, J. R. (2007). An associative classification-based recommendation system for personalization in B2C e-commerce applications. Expert Systems with Applications, 33(2):357-367. 